\section{Medical Principles and Practice}

Received: March 8, 2016

Accepted: September 7, 2016

Published online: September 7, 2016

Med Princ Pract 2017;26:93

DOI: $10.1159 / 000450647$

\title{
Intraocular Pressure during Continuous Positive Airway Pressure
}

Kuanxiao Hao, Xu Zhang

Affiliated Eye Hospital of Nanchang University, Jiangxi Research Institute of Ophthalmology and Visual Sciences, Nanchang, China

\section{Dear Editor,}

Obstructive sleep apnea (OSA) is a condition characterized by repetitive episodes of full or partial upper airway obstruction during sleep, leading to hypoxia and hypercapnia, and it is associated with other diseases such as heart disease, stroke, hypertension, diabetes mellitus and varied ocular morbidity [1].

Glaucoma, which is markedly characterized by progressive optic neuropathy and loss of visual field, is the second leading cause of blindness worldwide, often concomitantly appearing with elevated intraocular pressure (IOP), with current treatments mostly focusing on lowering the IOP [2]. Hypoxia caused by OSA can increase intracranial pressure during sleep, which subsequently leads to decreasing the cerebral perfusion pressure and influences the blood supply to the optic nerve [3].

Recently, a meta-analysis by Liu et al. [4] showed a positive association between OSA and the risk of glaucoma. Continuous positive airway pressure (CAPA) is undoubtedly considered the standard therapy for moderate and severe OSA as the first-choice treatment worldwide, and a constant nocturnal treatment with CAPA produces an obvious improvement in the quality of life of patients [5].

Over the past several decades, a number of studies have explored the effect of CAPA therapy on IOP in OSA patients, but with controversial outcomes [6-10]. In the cross-sectional study by Ulusoy et al. [6], the authors reported that OSA may be a risk factor for glaucoma. They showed that the use of CAPA therapy had positive and healing effects on glaucoma and recommended CAPA treatment for OSA patients to prevent the development of glaucoma. In 2010, Pepin et al. [7] reported that most patients with severe apnea have abnormal IOP rhythm and that the use of a nasal CAPA device recovered a normal 24-hour IOP rhythm. However, Cohen et al. [8] found that the IOP increased significantly when sleeping in the supine position and that CAPA did not have any effect on the measured IOP. Ultimately, the authors were still not sure about the feasibility of CAPA for treating OSA patients, and further studies were required to focus on the long-term effect of CAPA on IOP.

Kiekens et al. [9] claimed that patients with OSA had 24-hour IOP fluctuations, and, in addition, IOP increased with CAPA treatment, especially at night. This may be an important reason for

\section{KARGER}

E-Mail karger@karger.com www.karger.com/mpp (c) 2016 S. Karger AG, Basel

\section{Karger \\ Open access}

This is an Open Access article licensed under the terms of the Creative Commons Attribution-NonCommercial 3.0 Unported license (CC BY-NC) (www.karger.com/OA-license), applicable to the online version of the article only. Distribution permitted for non-commercial purposes only. the higher prevalence of glaucoma in OSA patients. A study by Chen et al. [10], on OSA patients receiving different treatments, showed that only the CPAP treatment could not decrease the risk of glaucoma.

The existing evidence concerning the effect on IOP during CAPA therapy is controversial, so the debate as to whether CAPA is safe for glaucomatous patients will persist. First, differences across studies might be explained by the study design; taking into consideration that IOP has a nyctohemeral rhythm in healthy subjects, the standardization of several factors that are known to affect nyctohemeral variation of the IOP during CAPA therapy is necessary. Second, it is essential to further summarize longitudinal data that is of a higher quality. CAPA treatment should be studied in randomized controlled trials and studies should have a longer follow-up time.

In summary, regarding whether or not CAPA therapy for treating OSA increases the IOP, the following suggestions should be considered. (1) Higher-quality prospective evidence and more comprehensive assessment are necessary to clarify the association between OSA, glaucoma and CAPA, and confounding factors should be adjusted. (2) Randomized controlled studies are needed to estimate the effect of CAPA therapy on IOP and the duration of follow-up should be extended. (3) Among sleep specialists and ophthalmic clinicians, there should be a greater awareness of the ocular condition associated with OSA, paying attention to the prevention of disease development by means of evaluation and followup (involving the IOP, optic disc and visual fields) in the clinical management of OSA patients, especially those treated with CAPA.

\section{References}

1 Montesi SB, Bajwa EK, Malhotra A: Biomarkers of sleep apnea. Chest 2012;142:239-245.

2 Cordeiro F, Tian K, Shibata-Germanos S, et al: Current perspective of neuroprotection and glaucoma. Clin Ophthalmol 2015;9:2109-2118.

3 Nusbaum DM, Wu SM, Frankfort BJ: Elevated intracranial pressure causes optic nerve and retinal ganglion cell degeneration in mice. Exp Eye Res 2015;136:38-44.

4 Liu S, Lin Y, Liu X: Meta-analysis of association of obstructive sleep apnea with glaucoma. J Glaucoma 2016;25:1-7.

5 Spicuzza L, Caruso D, Di Maria G: Obstructive sleep apnoea syndrome and its management. Ther Adv Chronic Dis 2015;6:273-285.

6 Ulusoy S, Erden M, Dinc ME, et al: Effects of use of a continuous positive airway pressure device on glaucoma. Med Sci Monit 2015;21:3415-3419.

7 Pepin JL, Chiquet C, Tamisier R, et al: Frequent loss of nyctohemeral rhythm of intraocular pressure restored by nCPAP treatment in patients with severe apnea. Arch Ophthalmol 2010;128:1257-1263.

8 Cohen Y, Ben-Mair E, Rosenzweig E, et al: The effect of nocturnal CPAP therapy on the intraocular pressure of patients with sleep apnea syndrome. Graefes Arch Clin Exp Ophthalmol 2015;253:2263-2271.

9 Kiekens S, Veva DG, Coeckelbergh T, et al: Continuous positive airway pressure therapy is associated with an increase in intraocular pressure in obstructive sleep apnea. Invest Ophthalmol Vis Sci 2008;49:934-940.

10 Chen $\mathrm{H}$, Chang Y, Lin C, et al: Obstructive sleep apnea patients having surgery are less associated with glaucoma. J Ophthalmol 2014;2014:1-6. 